\title{
Doxycycline in Extremely Low Dose Improves Glycemic Control and Islet Morphology in Mice Fed a High-Fat Diet
}

This article was published in the following Dove Press journal: Diabetes, Metabolic Syndrome and Obesity: Targets and Therapy

\author{
Yixin Chen' \\ Yu Chen ${ }^{2}$ \\ $\mathrm{Na} \mathrm{Wang}{ }^{2}$ \\ Shanhong Gu' \\ Meilin Wang' \\ Yucai $\mathrm{Fu}^{3}$ \\ Chiju Wei ${ }^{2}$ \\ Wencan $\mathrm{Xu}^{\mathrm{I}}$ \\ 'Department of Endocrinology, The First \\ Affiliated Hospital of Shantou University \\ Medical College, Shantou, Guangdong, \\ 5I504I, People's Republic of China; \\ ${ }^{2}$ Laboratory of Molecular Biology, \\ Multidisciplinary Research Center, \\ Shantou University, Shantou, Guangdong, \\ 5I5063, People's Republic of China; \\ ${ }^{3}$ Laboratory of Cell Senescence, Shantou \\ University Medical College, Shantou, \\ Guangdong, 51504I, People's Republic of \\ China
}

Purpose: Chronic low-grade inflammation is detected in obese and diabetic individuals. Tetracyclines, used as antibiotics for years, have been demonstrated to have diverse nonbactericidal effects, including anti-tumor and anti-inflammatory activities. This study aimed to investigate whether doxycycline at sub-antimicrobial concentrations could improve glycemic control in mice fed a high-fat diet, through its anti-inflammatory activities.

Methods: C57BL/6J mice were fed with a high-fat diet to induce diabetic and obese conditions. Three sub-antimicrobial dosages of doxycycline $(200,20$, and $2 \mu \mathrm{g} / \mathrm{mL})$ were added to drinking water for 23 weeks during the housing phase.

Results: Doxycycline at $200 \mu \mathrm{g} / \mathrm{mL}$ tended to increase body weight, islet mass, and the percentage of large islets (diameter $>350 \mu \mathrm{m}$ ). At $20 \mu \mathrm{g} / \mathrm{mL}$, doxycycline significantly improved glucose tolerance and decreased fasting blood glucose. At $2 \mu \mathrm{g} / \mathrm{mL}$, doxycycline increased the percentage of small islets (diameter $<80 \mu \mathrm{m}$ ). Serum C-reactive protein and lipopolysaccharide levels significantly decreased while the beta-cell ratio increased in all doxycycline-administered mice.

Conclusion: Our results suggest that doxycycline, even at an extremely low dose, could improve glycemic control and islet morphology via its anti-inflammatory activities.

Keywords: doxycycline, inflammation, T2DM, diabetes, glucose metabolism

\section{Introduction}

The popularity of the Western diet, characterized by an excessive intake of refined sugars, salt, and saturated fat, increases the population of people with obesity and type 2 diabetes (T2DM). Patients who have disorders of lipid and sugar metabolism have a condition called chronic low-grade inflammation. ${ }^{1}$ Proinflammatory mediators released from obese adipose tissue trigger the inflammatory reaction in insulin target organs (liver, muscles, adipose tissue, etc), leading to the development of insulin resistance. ${ }^{2}$ Inflammatory cells gradually infiltrate the pancreatic islets, causing betacell dysfunction and apoptosis, and eventually resulting in an absolute lack of insulin. ${ }^{3,4}$ Anti-inflammatory drugs may have huge potential for T2DM therapy.

Tetracyclines, which have been used as antibiotics for years, have been demonstrated to have diverse non-bactericidal effects such as anti-tumor and antiinflammatory activities. ${ }^{5,6}$ Tetracyclines can suppress matrix metalloproteinase (MMPs) and proinflammatory cytokines, ${ }^{7}$ and have been extensively investigated in cardiovascular and neurological disorders. ${ }^{8,9}$ Doxycycline is one of the most
Correspondence: Chiju Wei

Shantou University, 243 Daxue Road

Republic of China

Email chijuwei@stu.edu.cn

Wencan Xu

Department of Endocrinology, The First Affiliated Hospital of Shantou University

Medical College, 57 Changping Road,

Shantou, Guangdong, 5I504I, People's

Republic of China

Email xuwcan@I63.com
Diabetes, Metabolic Syndrome and Obesity: Targets and Therapy 2021:14 637-646

637

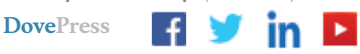

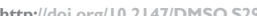


widely used tetracyclines today. Our previous study showed that low-dose doxycycline decreased systemic inflammation and improved glycemic control, lipid profiles, and islet morphology in $\mathrm{db} / \mathrm{db}$ mice. ${ }^{10}$ In this study, to overcome the concern of causing antibiotic resistance, doxycycline in three sub-antimicrobial dosages was added to drinking water and provided to 6-week-old male C57BL/6J mice for 23 weeks. Mice fed a high-fat diet (HFD) developed diet-induced obesity (DIO) and hyperglycemia, and were used as a model for T2DM. The results suggested that long-term administration of subantimicrobial doxycycline could be a novel therapeutic strategy for T2DM treatment.

\section{Methods}

\section{Animals and Housing}

Three- to four-week-old male $\mathrm{C} 57 \mathrm{BL} / 6 \mathrm{~J}$ mice were obtained from Beijing HFK Bioscience (China) and housed in an air-conditioned animal facility. After 3 weeks' adaptation, mice were weighed then randomly divided into four HFD-treated groups (Control, DC2, DC20, and DC200, representing 0, 2, 20, and $200 \mu \mathrm{g} / \mathrm{mL}$ doxycycline in drinking water, respectively) and one normal control group (NC). NC was set as a healthy group aiming to evaluate whether and when the obese and diabetic conditions had been induced successfully. Each experimental group contained 15 mice and each control group contained nine mice. Three mice were in one cage. The above doxycycline concentrations were chosen based on previous studies. ${ }^{11}$ All mice had free access to water, and HFD-treated groups were fed ad libitum with a $60 \mathrm{kcal}$ $\%$ high-fat diet (Research Diets, D12495). Doxycycline was added to drinking water and the water bottles were protected from light. The normal control group (NC) was fed ad libitum with a $10 \mathrm{kcal} \%$ regular diet (HFK Bioscience, H10010) and drank regular water.

The housing phase lasted for 23 weeks. Weights were recorded every week. At the 19th week, body weights of the HFD-treated groups were $20 \%$ higher than those in $\mathrm{NC}$, indicating that the obesity model had been successfully built. Between 20 and 23 weeks, mice were fasted for hours to measure blood glucose and perform intraperitoneal glucose and insulin tolerance tests (IPGTT and IPITT). For this reason, food and water consumption was measured every 3 days until 19 weeks. All study methods and procedures were approved by and performed in strict accordance with the relevant regulations and guidelines of the Animal Care and Use Committee of Shantou University.

\section{Blood and Tissue Collection}

At the end of the experiment, mice were anesthetized by intraperitoneal injection of pentobarbital $(100 \mathrm{mg} / \mathrm{kg}$ body weight). Sera were separated, then stored at $-80^{\circ} \mathrm{C}$ before use. Pancreases were fixed with $4 \%$ paraformaldehyde for $\mathrm{H} \& \mathrm{E}$ staining. Lee's index $=\sqrt[3]{\text { Body Weight }(\mathrm{g}) \times 10^{3} / \text { Body Length }(\mathrm{cm})}$.

Epididymal and peritoneal fat was harvested and weighed.

\section{Serum Biochemical and Inflammatory Parameters}

Serum glucose was measured using an automatic Unicel DxC 800 Chemistry Analyzer (Beckman Coulter, Brea, $\mathrm{CA})$ in the First Affiliated Hospital of Shantou University. Serum C-reactive protein (CRP; Lanpai Biotechnology, Shanghai) and lipopolysaccharide (LPS; Luao Biotechnology, Shanghai) were measured by enzyme-linked immunosorbent assay (ELISA).

\section{Intraperitoneal Glucose Tolerance Test (IPGTT) and Insulin Tolerance Test (ITT)}

Blood glucose levels in the tail vein were measured using a Sannuo glucometer (Sannuo, China). We carried out the IPGTT and IPITT at the 20th and 22nd week, respectively. For the IPGTT, mice were fasted for $8 \mathrm{~h}$ and the blood glucose was measured at $0,15,30,60$, and $120 \mathrm{~min}$ after intraperitoneal injection of glucose $(1 \mathrm{~g} / \mathrm{kg} \mathrm{bw})$. For the ITT, mice were fasted for $6 \mathrm{~h}$, then insulin $(1 \mathrm{U} / \mathrm{kg} \mathrm{bw}$, from Gansulin R, Tonghua Dongbao Pharmaceutical, China) was injected intraperitoneally, and blood glucose was measured at $0,15,30,60$, and $120 \mathrm{~min}$.

\section{Determination of Islet Mass and Size}

Islet mass and size were evaluated by the previously reported morphometric method, based on H\&E staining. ${ }^{12}$ We randomly chose five mice per group. In brief, each paraffin block of the pancreas was sectioned consecutively at $5 \mu \mathrm{m}$ thickness. About 30 slides (each separated by $100 \mu \mathrm{m}$ ) from each pancreas were chosen for $\mathrm{H} \& \mathrm{E}$ staining. Pancreas images were captured under a microscope. To determine the area on images, islets were picked out manually with tools in Image-Pro Plus 6.0. Islet numbers and islet size were counted on each slide. 


\section{Immunofluorescence Staining (IF) of the Pancreas}

Sections were incubated with goat anti-insulin (sc-7839; Santa Cruz, Santa Cruz, CA) at $4^{\circ} \mathrm{C}$ overnight, then incubated with cy3-conjugated donkey anti-goat (A0502; Beyotime, China) at $37^{\circ} \mathrm{C}$ for $2 \mathrm{~h}$. The nucleus was stained with Hoechst 33342 (B8040; Solarbio, China) after washing with PBS. Three sections were randomly chosen from each mouse in each group (about 80 islets in each group) for IF study. Images were captured under equal exposure conditions and the same magnification $(20 \times$ objective lens), then analyzed using Image-Pro Plus 6.0 software.

\section{Statistics}

The results are shown as the mean \pm SEM. All statistical analysis was performed using ANOVO in GraphPad Prism 8.0. Values of $p<0.05$ were considered significant.

\section{Results}

\section{Doxycycline Treatment Increased Food} Intake and Weight in HFD-Treated Mice

Food intake was monitored from 1 to 19 weeks during the housing phase (Figure 1A). Doxycycline administration tended to stimulate food intake but showed no significant differences compared to the control group (Figure 1B). The weights of NC, control, DC200, DC20, and DC2 were 29.01, 39.96, 46.41, 40.33, and 41.32 g, respectively. The HFD treatment resulted in higher body weight in mice compared to the NC group fed standard food (Figure 1C). Greater food intake in the DC200 group consequently led to significantly increased body weights, with an average of $46.41 \mathrm{~g}$, compared to the control group of $39.96 \mathrm{~g}$ (Figure 1D). Lee's index and the weight of adipose tissue increased correspondingly in the DC200 group (Figure 1E and F).

\section{Doxycycline Decreased Triglycerides in HFD-Treated Mice but Had No Influence on Other Serum Lipids}

Levels of serum lipids in HFD-treated mice were significantly higher than those in NC mice (Figure 2). The mean values of serum triglycerides (TG) in the doxycycline treatment groups were between 0.81 and $0.87 \mathrm{mmol} / \mathrm{L}$, compared to $1.04 \mathrm{mmol} / \mathrm{L}$ in the control group. However, serum levels of total cholesterol (TC), low-density lipoprotein (LDL), and high-density lipoprotein (HDL) were not affected significantly by doxycycline treatment (Figure 2A, C and D).
Doxycycline Decreased Fasting Blood Glucose and Improved the Glucose Response in HFD-Treated Mice

Mean values of fasting blood glucose (FBG) in the NC and DC2 groups were 8.81 and $9.74 \mathrm{mmol} / \mathrm{L}$, respectively, which were lower than in the other HFD-treated mice and significantly lower than $11.7 \mathrm{mmol} / \mathrm{L}$ in the control group (Figure 3E). The PGTT was then carried out (Figure 3A), and the area under the curve (AUC) of the IPGTT of the DC20 group was reduced by about $20 \%$ compared to that of the control group (Figure 3B), suggesting improved glucose tolerance. An insulin tolerance test (ITT) was also performed (Figure 3C), and the AUC of the ITT was reduced in DC20/DC2 mice, but not significantly so (Figure 3D).

\section{Doxycycline Increased Islet Number in HFD-Treated Mice}

To determine islet number and islet mass, H\&E staining of the pancreas was carried out (Figure 4D) Compared to the control group, islet number increased by about $25 \%$ in DC2 but was not significantly affected by other doxycycline doses (Figure 4A). Total islet mass increased by about $35 \%$ in DC200 (Figure 4B). To better understand the relationship between islet number and islet mass, islet number was plotted against islet size (Figure 4C). Small islets (30-80 $\mu \mathrm{m}$ in diameter) increased in number in DC2, while large islets ( $\geq 350 \mu \mathrm{m}$ in diameter) decreased significantly. In contrast, the number of large islets increased significantly in DC200, while the number of small islets did not change.

\section{Doxycycline Increased the Beta-Cell Ratio and Beta-Cell Mass}

To determine the beta-cell ratio and beta-cell mass, immunofluorescence staining of insulin in the pancreas was performed (Figure 5C). The beta-cell ratios of DC200, DC20 and DC2 were $79.81 \%, 81.64 \%$, and $82.33 \%$, respectively, which were significantly higher than those of the control group (73.29\%) (Figure 5A). The beta-cell mass (BCM) also increased in all doxycycline-treated groups (Figure 5B).

\section{Doxycycline Decreased Systemic Inflammation in HFD-Treated Mice}

Serum levels of CRP and LPS, reflecting the extent of systemic inflammation, were determined by ELISA. The results showed that both CRP and LPS decreased significantly in the doxycycline-treated group. CRP decreased from $827.41 \mathrm{pg} / \mathrm{mL}$ in the 

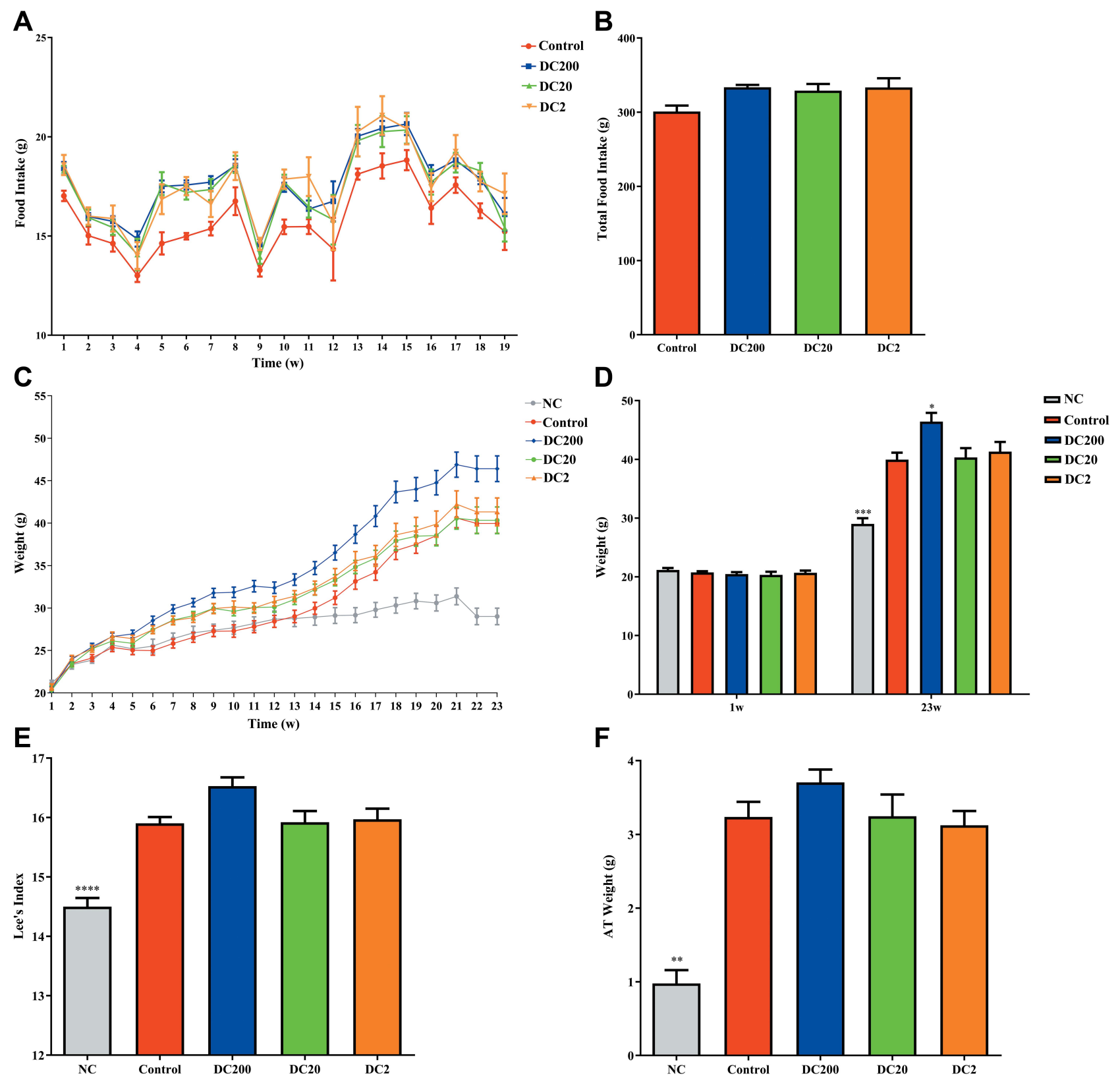

Figure I Doxycycline increased food intake and body weight. (A) Food intake at weeks I-I9; (B) total food intake of mice fed HFD; (C) body weight at I-23 weeks of mice fed HFD and standard food; (D) body weight at I and 23 weeks of mice fed HFD or standard food; (E) Lee's

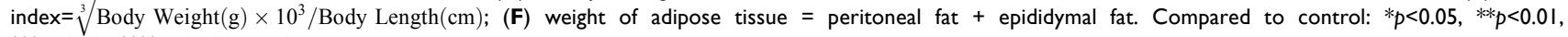
$* * * p<0.001$, **** $p<0.0001$. $n=9-15$.

control group to $701.65,671.46$, and $703.49 \mathrm{pg} / \mathrm{mL}$, respectively, in DC200, DC20, and DC2 (Figure 6A). Doxycycline treatment dramatically decreased the LPS levels in HFDtreated mice, by about $26-47 \%$ (Figure $6 \mathrm{~B}$ ).

\section{Discussion}

A previous study using $\mathrm{db} / \mathrm{db}$ mice showed that $100-200 \mu \mathrm{g} /$ $\mathrm{mL}$ of doxycycline in drinking water resulted in a serum concentration of $83-144 \mathrm{ng} / \mathrm{mL},{ }^{10}$ which was a more than
1000 -fold reduction and significantly lower than the antibacterial dose of $1-3 \mu \mathrm{g} / \mathrm{mL} .{ }^{13}$ In the present study, to further alleviate the concerns over causing antibiotic resistance, the effect of three dosages of doxycycline in sub-antimicrobial concentrations was further investigated in HFD-treated mice. If the same reduction rate is applied to this study, serum doxycycline could be as low as $1 \mathrm{ng} / \mathrm{mL}$, which is 1000 fold lower than the bactericidal concentration. It has been known for a long time that antibiotics can modulate the gut 
A

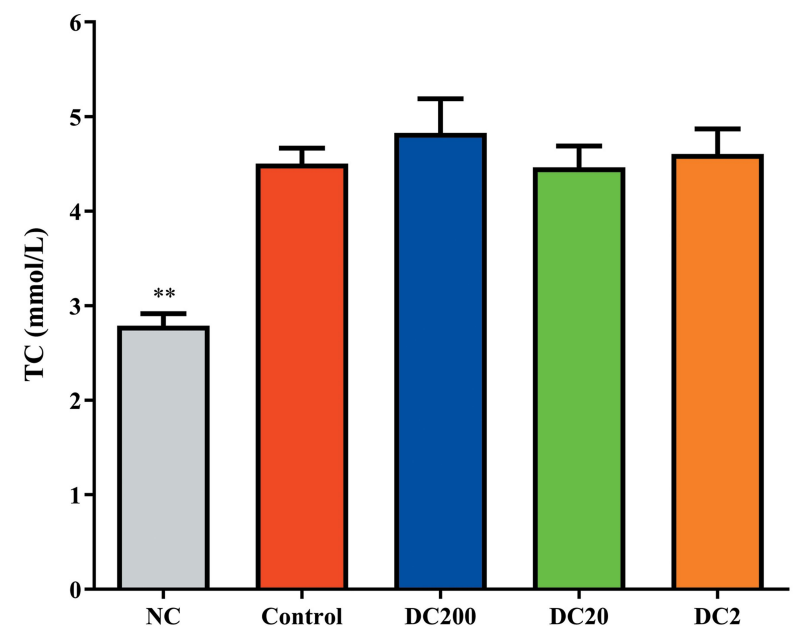

C

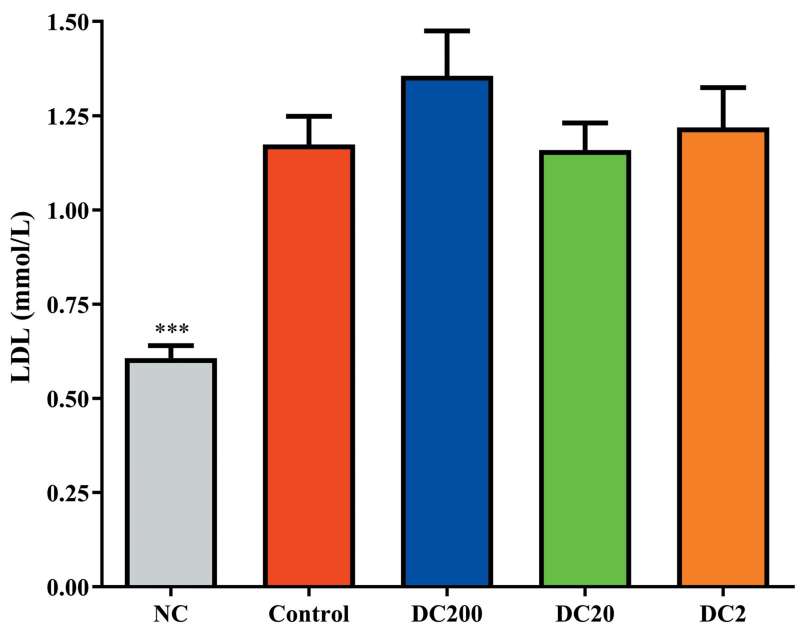

B

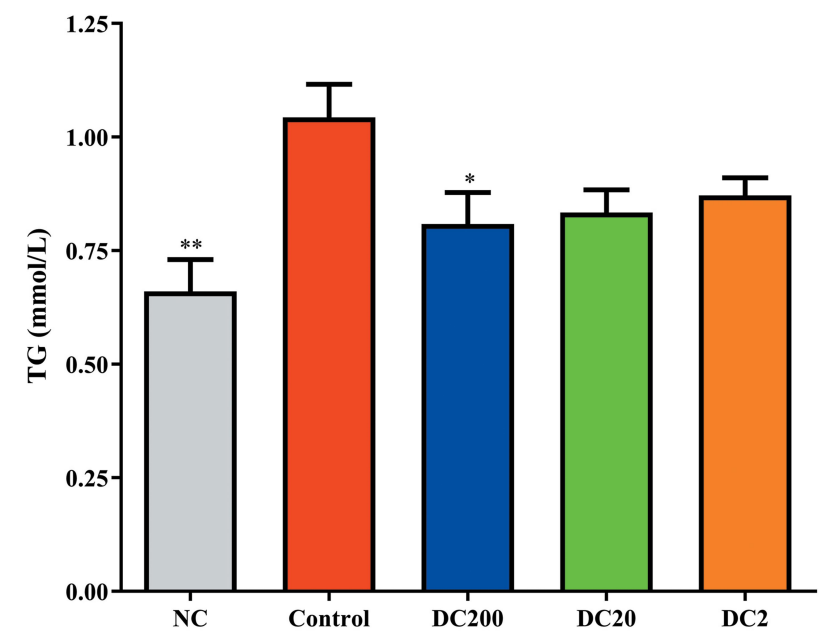

D

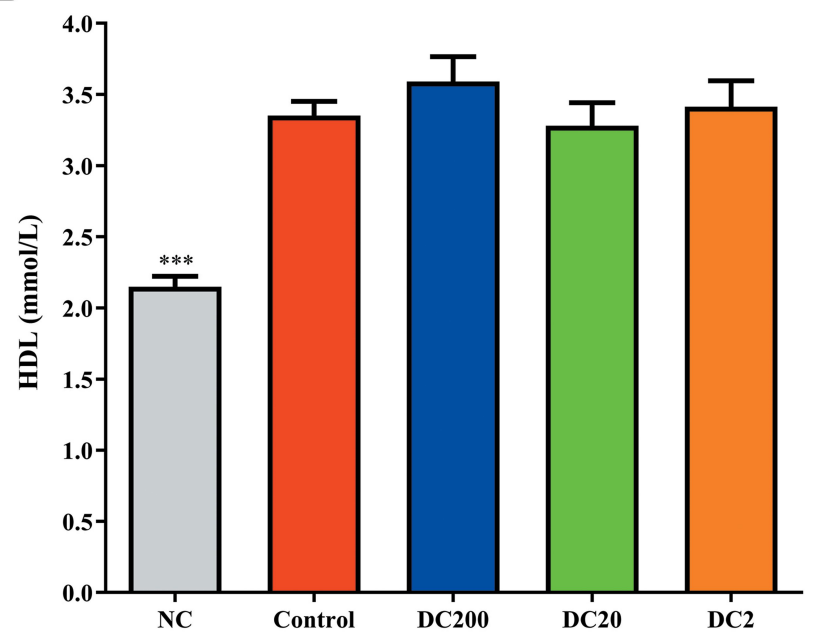

Figure 2 Doxycycline decreased serum lipid levels. (A) Total cholesterol (TC); (B) triglyceride (TG); (C) low-density lipoprotein (LDL); (D) high-density lipoprotein (HDL). Compared to control: $* p<0.05,{ }^{* *} p<0.01$, ${ }^{* * *} p<0.001$. $n=9$.

microbiota, ${ }^{14}$ and long-term treatment with doxycycline and hydroxychloroquine in patients with $\mathrm{Q}$ fever endocarditis has been found to lower concentrations of Bacteroidetes, Firmicutes, Lactobacillus, and total bacteria. ${ }^{15}$ We did not look into the perturbation of the microbiota, but a comparison of doxycycline concentration used in this study and others would suggest a minimal influence of gut bacteria with subbactericidal doxycycline, especially at a concentration of 2 $\mu \mathrm{g} / \mathrm{mL}$. Alternatively, to avoid killing gut microbiota, doxycycline at a much lower concentration could be injected directly into the blood circulation.

Nonetheless, the results in the present study demonstrated that doxycycline administration could increase food intake (Figure 1A and B). Appetite was influenced by doxycycline at all tested doses. This effect thus led to higher body weights in DC200 than in the other groups. Correspondingly, Lee's index and adipose tissue weight turned out to be higher in the DC200 group (Figure 1E and F). Furthermore, doxycycline administration decreased blood triglyceride levels, but had no effect on total cholesterol, HDL, or LDL (Figure 2). DC200 also had slightly higher total cholesterol, HDL, and LDL levels, showing again that higher doxycycline doses may have adverse effects on metabolism. Veterinary scientists have shown that adding sub-therapeutic doses of antibiotics to food or water results in the promotion of growth. This growth promotion effect was found regardless of class of antibiotic, mode of action, and anti-bacterial spectrum. ${ }^{16}$ Studies on humans have also demonstrated that antibiotic treatment in early life can increase the likelihood of 
A

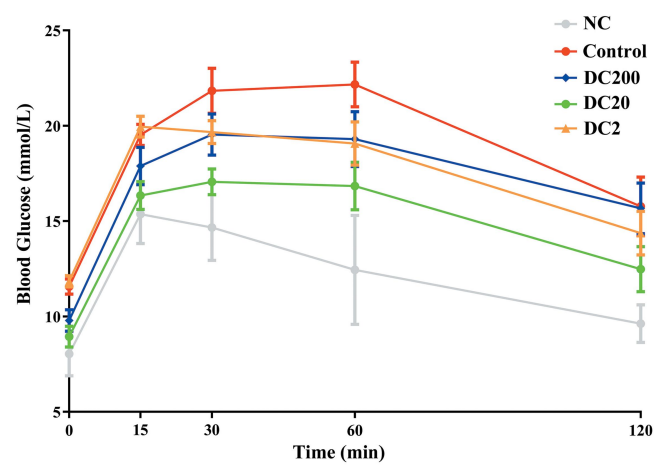

C

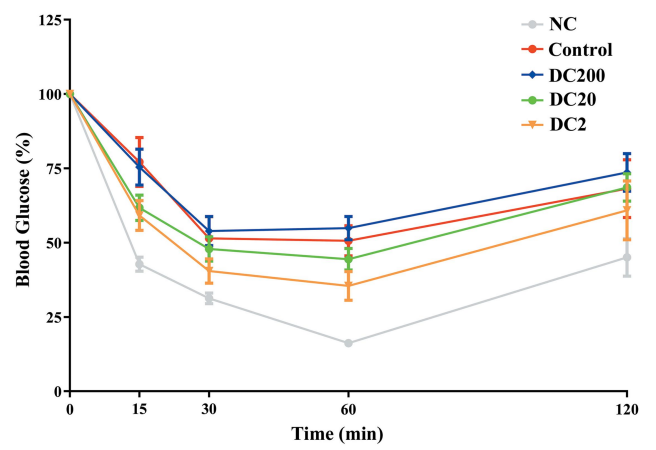

B

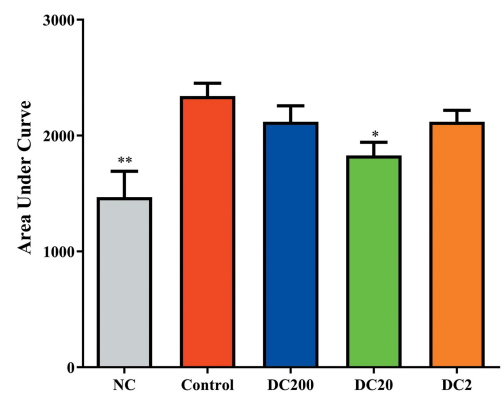

D

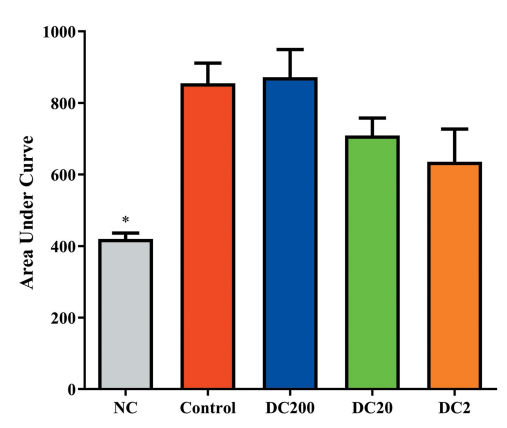

E

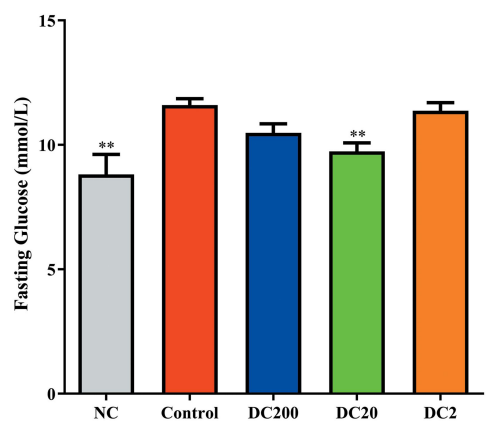

Figure 3 Doxycycline decreased FBG and improved glucose tolerance. (A) Intraperitoneal glucose tolerance test (IPGTT); (B) area under the curve (AUC) of IPGTT; (C) insulin tolerance test (ITT); (D) AUC of ITT; (E) fasting blood glucose (FBG). Compared to control: $* p<0.05, * * p<0.01$. $n=9-15$.

obesity in the long term. ${ }^{17,18}$ Our study showed that the growth-promoting effect may be due to the increase in food consumption.

One striking observation of our study was that doxycycline could improve the glucose response in HFD-treated mice. In our previous experiment in $\mathrm{db} / \mathrm{db}$ and $\mathrm{Balb} / \mathrm{c}$ mice, we observed that doxycycline treatment could stimulate glucose-stimulated insulin secretion. ${ }^{10}$ In the present study, lower blood glucose and better IPGTT response were found in the DC20 group (Figure 3A, B and E). The ITT study also showed that doxycycline tended to improve insulin resistance (Figure 3C and D). It should be noted that DC200 did not adversely affect glucose and insulin tolerance, probably owing to its pleiotropic effects on inflammation (Figure 6). It has been reported that insulin resistance could be the consequence of inflammation caused by glucotoxicity and lipotoxicity. ${ }^{19,20}$ CRP, as a systemic inflammatory marker, decreased after doxycycline treatment (Figure 6A). Many other studies have confirmed the anti-inflammatory activity of doxycycline. ${ }^{5,21,22}$ Decreases in serum glucose and triglyceride levels after doxycycline treatment may contribute to the decreased glucotoxicity and lipotoxicity. ${ }^{23}$ LPS produced by the intestinal microbiota has been shown to participate in the development of obesity. ${ }^{24,25}$ Doxycycline could also decrease serum LPS (Figure 6B). However, we are not sure whether doxycycline decreased LPS via the inhibition of gut microbiota or the reduction of epithelial cell permeability in the intestine. The DC200 group had higher LPS levels compared to DC20 and DC2, which was in agreement with the findings of body and adipose tissue weight (Figure 1).

An important observation in the present study was the smaller size but higher number of islets found in the DC2 group (Figure 4). Contrary to this result, islet size increases after the administration of metformin or pioglitazone in diabetic animals. ${ }^{26,27}$ We reported previously that islet size increased while mitotic activity decreased as the animal grew older, ${ }^{12}$ suggesting that smaller islets might be younger in age. The finding could be in consistent with a recent report that mitochondrial imbalance caused by doxycycline treatment could lead to longevity in worms and mice. ${ }^{28}$ In the DC20 group, the number of small islets $(30-80 \mu \mathrm{m})$ also increased while the number of large islets ( $\geq 350 \mu \mathrm{m}$ ) decreased significantly. On the other hand, the DC200 group had a significantly increased 
A
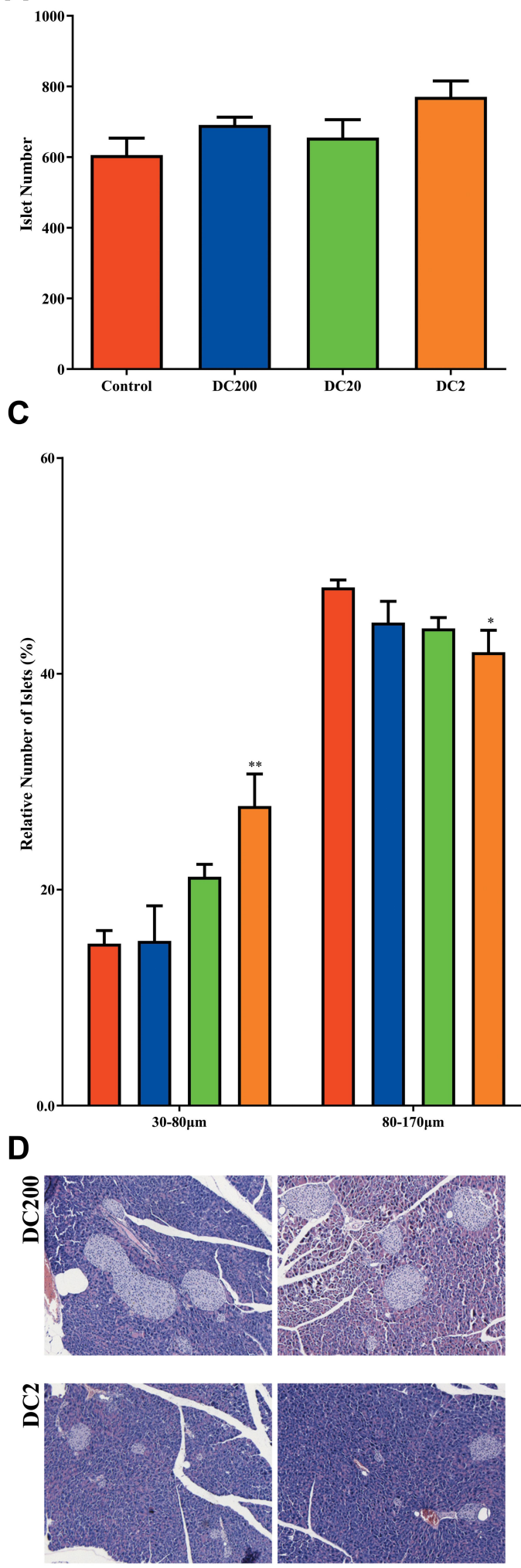

B

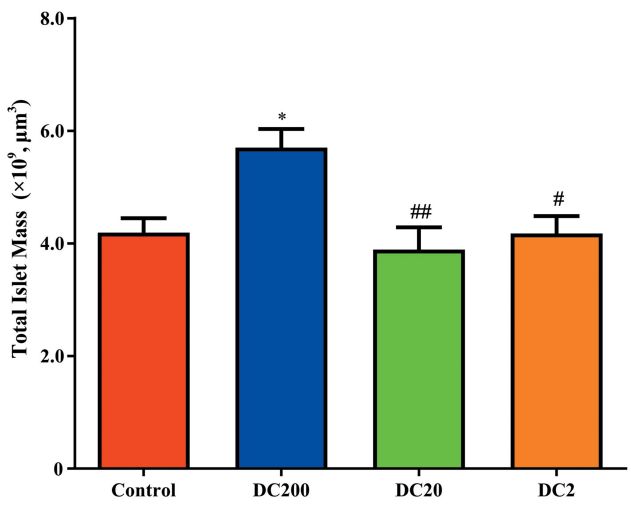

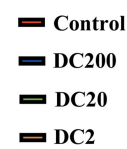

च DC2

Figure 4 Doxycycline improved islet morphology in HFD-treated mice. (A) Total islet number; (B) total islet mass; (C) distribution of islet size. (D) H\&E staining of pancreases. Compared to control: ${ }^{*} p<0.05$, ${ }^{* *} p<0.01$. Compared to DC200: $\# p<0.05$, \#p<0.01. $n=5$. 
A

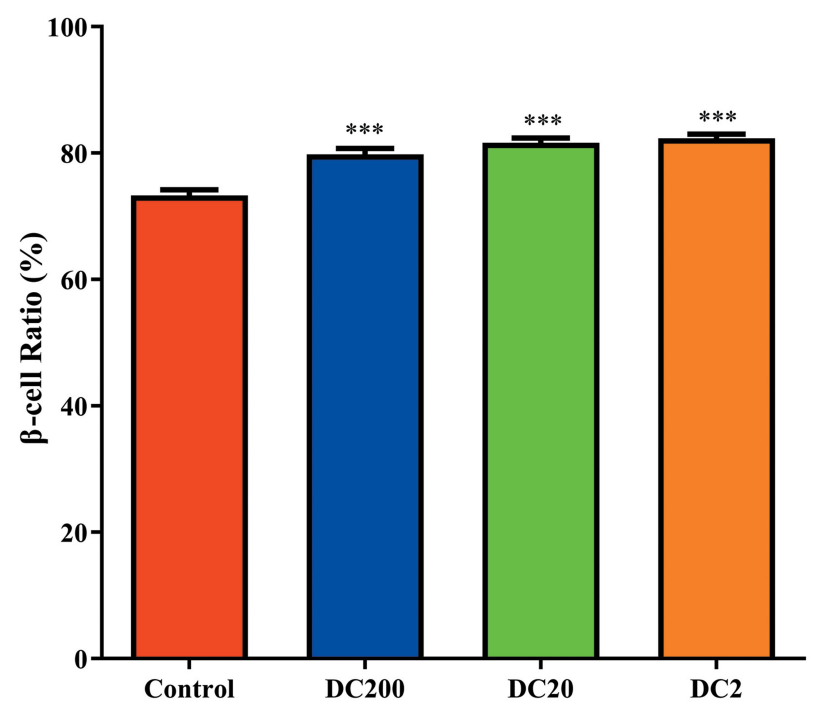

C
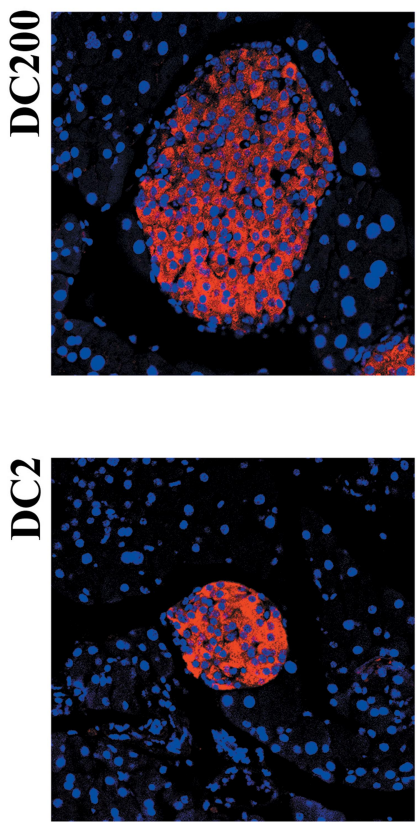

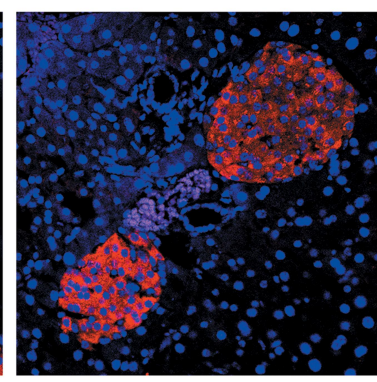

రิ
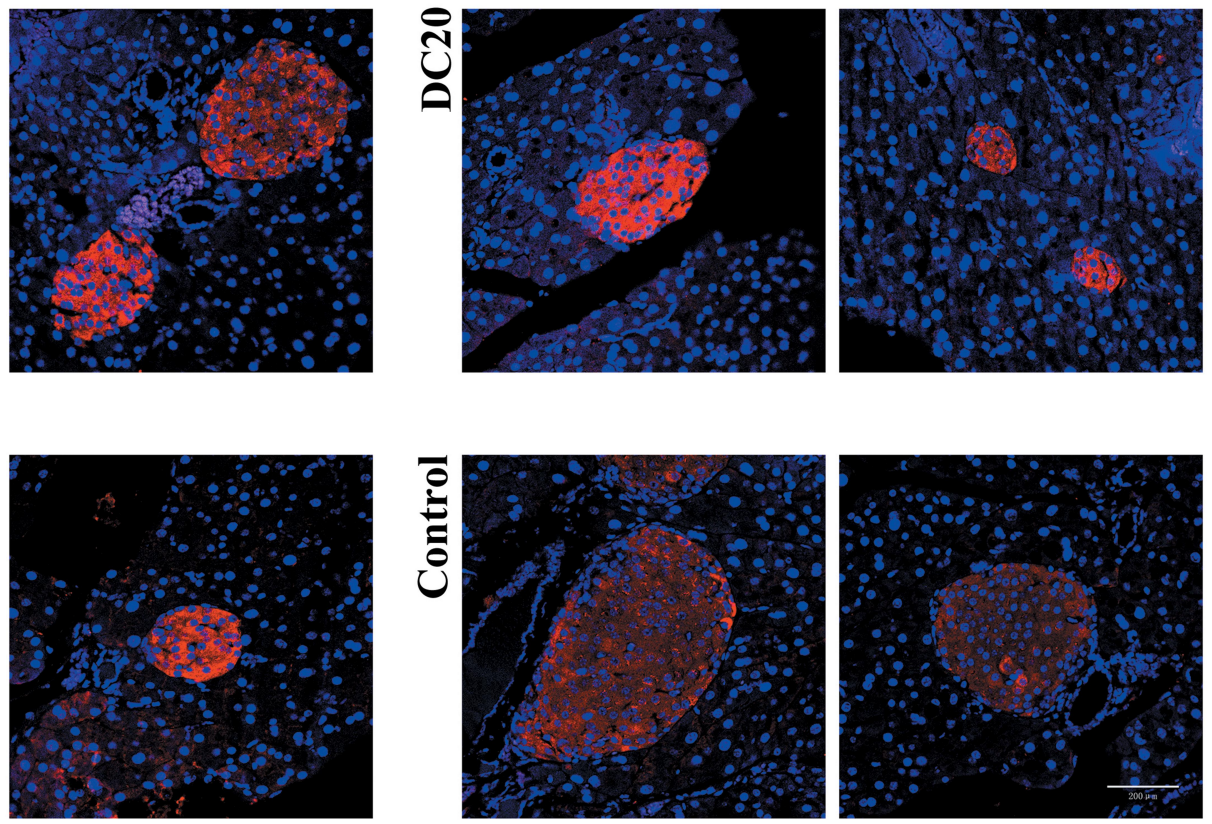

B

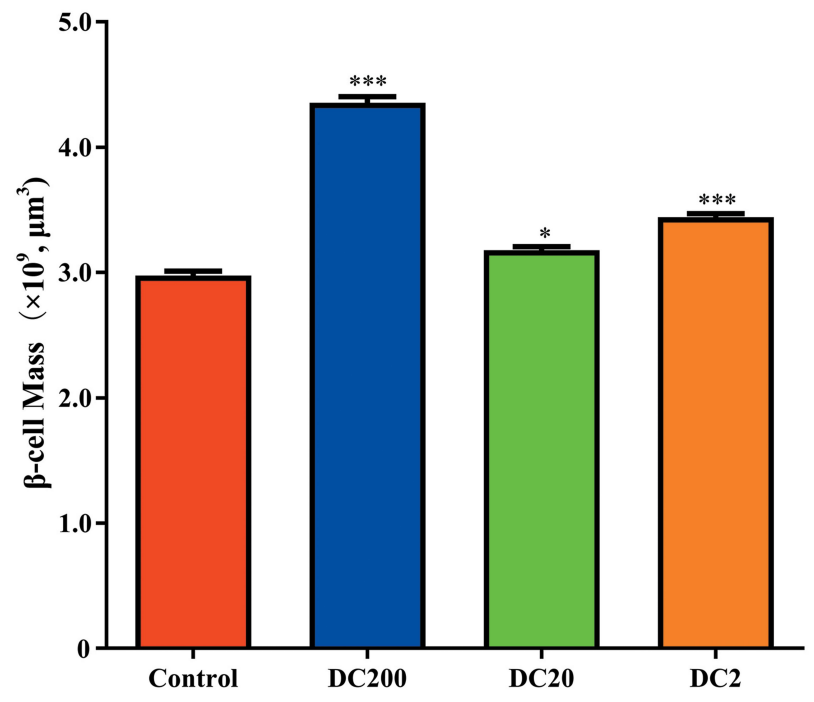

Figure 5 Doxycycline increased beta-cell mass in HFD-treated mice. (A) Beta-cell ratio; (B) beta-cell mass. (C) Insulin (red) and Hoechst (blue) staining of pancreases. Compared to control: ${ }^{*} p<0.05, * * * p<0.00$ I. $n=80$.

number of larger islets and thus dramatically higher total islet mass, which probably compensated for the increased body and adipose tissue weight. In obese and diabetic individuals, the expanding demand for insulin secretion is accommodated by the hypertrophy and proliferation of beta-cells, instead of neogenesis. ${ }^{29}$ Therefore, the higher number of large islets observed in DC200 mice was indicative of beta-cell hypertrophy and proliferation. On the other hand, the higher number of small islets found in DC20 and DC2 was consistent with neogenesis of islet beta-cells. Moreover, doxycycline increased both the betacell ratio and beta-cell mass, although the trend was slightly different in each group (Figure 5). In any event, the results were consistent with better glucose and insulin tolerance in HFD-induced obese mice treated with doxycycline. 
A

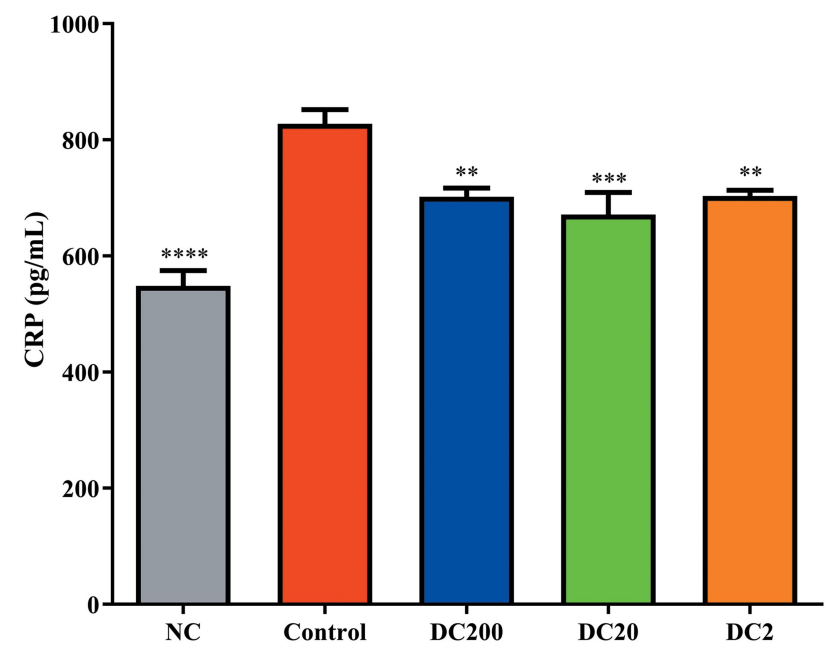

B

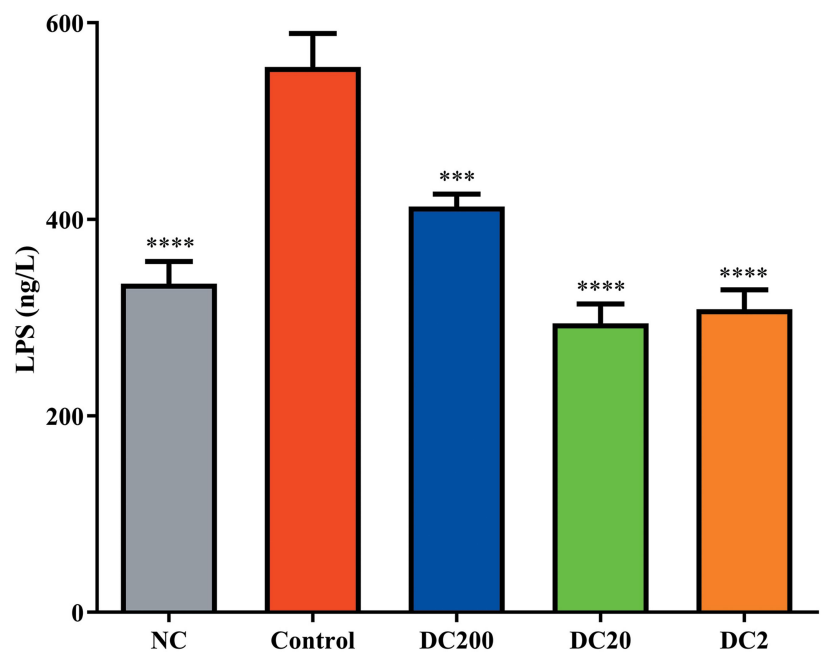

Figure 6 Doxycycline suppressed systemic inflammation. (A) Serum C-reactive protein (CRP); (B) serum lipopolysaccharide (LPS). Compared to control: **p<0.0I, $* * * p<0.001$, $* * * * p<0.0001 . \mathrm{n}=6$.

In conclusion, we demonstrated that doxycycline in extremely low doses could improve glucose tolerance and islet morphology in mice fed a high-fat diet. The effect varied between each doxycycline treatment group, probably reflecting the pleiotropic functions of doxycycline in different doses. However, the exact mechanism underlying these observations is still unclear and needs further investigation.

\section{Funding}

This study was supported by grants from the National Natural Science Foundation of China (grant numbers 30971665, 81172894, 81370925), the Natural Science Foundation of Guangdong Province (project number 2020A1515011100), and Key Project of Shantou Office of Science and Technology (2016-30).

\section{Disclosure}

The authors declare that there are no conflicts of interest.

\section{References}

1. Van GMMJ, Schalkwijk CG, Stehouwer CDA. Dysfunctional adipose tissue and low-grade inflammation in the management of the metabolic syndrome: current practices and future advances. F1000research. 2016;5:2515. doi:10.12688/f1000research.8971.1

2. Nunemaker CS. Considerations for defining cytokine dose, duration, and milieu that are appropriate for modeling chronic low-grade inflammation in type 2 diabetes. $J$ Diabetes Res. 2016;2016:2846570. doi: $10.1155 / 2016 / 2846570$

3. Quan W, Jo EK, Lee MS. Role of pancreatic $\beta$-cell death and inflammation in diabetes. Diabetes Obes Metab. 2013;15(s3):141-151. doi:10.1111/dom.12153
4. Collier JJ, Sparer TE, Karlstad MD, Burke SJ. Pancreatic islet inflammation: an emerging role for chemokines. $J$ Mol Endocrinol. 2017;59(1):R33. doi:10.1530/JME-17-0042

5. Han L, Su W, Huang J, Zhou J, Qiu S, Liang D. Doxycycline inhibits inflammation-induced lymphangiogenesis in mouse cornea by multiple mechanisms. PLoS One. 2014;9(9):e108931. doi:10.1371/journal. pone. 0108931

6. Bahrami F, Morris L, Pourgholami M. Tetracyclines: drugs with Huge Therapeutic Potential. Mini Rev Med Chem. 2012;12 (1):44-52. doi:10.2174/138955712798868977

7. Dorma G, Cseh S, Hajda I, et al. Matrix metalloproteinase inhibitors: a critical appraisal of design principles and proposed therapeutic utility. Drugs. 2015;70(8):949-964. doi:10.2165/11318390000000000-00000

8. Duncan I, Kesicki W. Tetracycline derivatives with reduced antibiotic activity and neuroprotective benefits. 2018.

9. Griffin MO, Fricovsky E, Ceballos G, Villarreal F. Tetracyclines: a pleitropic family of compounds with promising therapeutic properties. Review of the literature. Am J Physiol Cell Physiol. 2010;299 (3):C539. doi:10.1152/ajpcell.00047.2010

10. Wang N, Tian X, Chen Y, et al. Low dose doxycycline decreases systemic inflammation and improves glycemic control, lipid profiles, and islet morphology and function in db/db mice. Sci Rep. 2017;7:1.

11. Traykova-Brauch M, Schnig K, Greiner O, et al. An efficient and versatile system for acute and chronic modulation of renal tubular function in transgenic mice. Nat Med. 2008;14(9):979-984. doi:10.1038/nm.1865

12. Peng SW, Zhu LY, Chen M, et al. Heterogeneity in mitotic activity and telomere length implies an important role of young islets in the maintenance of islet mass in the adult pancreas. Endocrinology. 2009;150(7):3058-3066. doi:10.1210/en.2008-1731

13. Clinical and Laboratory Standards Institute. Performance Standards for Antimicrobial Susceptibility Testing. Vol. 30; 2001.

14. Gianluca I, Herbert T, Antonio G. Antibiotics as deep modulators of gut microbiota: between good and evil. Gut. 2016;1:254.

15. Angelakis E, Million M, Kankoe S, et al. Abnormal weight gain and gut microbiota modifications are side effects of long-term doxycycline and hydroxychloroquine treatment. Antimicrob Agents Chemother. 2014;58(6):3342-3347. doi:10.1128/AAC.02437-14

16. Jukes TH, Williams WL. Nutritional Effects of Antibiotics. Pharmacol Rev. 1953;5(4):381. 
17. Cox LM, Blaser MJ. Antibiotics in early life and obesity. Nat Rev Endocrinol. 2015;11(3):182-190. doi:10.1038/nrendo.2014.210

18. Zeissig S, Blumberg RS. Life at the beginning: perturbation of the microbiota by antibiotics in early life and its role in health and disease. Nat Immunol. 2014;15(4):307-310. doi:10.1038/ni.2847

19. Fresno M, Alvarez R, Cuesta N. Toll-like receptors, inflammation, metabolism and obesity. Arch Physiol Biochem. 2011;117 (3):151-164. doi:10.3109/13813455.2011.562514

20. Cai D, Yuan M, Frantz DF, et al. Local and systemic insulin resistance resulting from hepatic activation of IKK- $\beta$ and NF-kB. Nat Med. 2005;11(2):183. doi:10.1038/nm1166

21. Cazalis J, Bodet C, Gagnon G, Grenier D. Doxycycline Reduces Lipopolysaccharide-Induced Inflammatory Mediator Secretion in Macrophage and Ex Vivo Human Whole Blood Models. J Periodontol. 2008;79(9):1762-1768. doi:10.1902/jop.2008.080051

22. Lee CZ, Xu B, Hashimoto T, Mcculloch CE, Yang GY, Young WL. Doxycycline suppresses cerebral matrix metalloproteinase- 9 and angiogenesis induced by focal hyperstimulation of vascular endothelial growth factor in a mouse model. $j$ Cerebral Circulation. 2004;35 (7):1715-1719. doi:10.1161/01.STR.0000129334.05181.b6

23. Cani PD, Amar J, Iglesias MA, et al. Metabolic endotoxemia initiates obesity and insulin resistance. Diabetes. 2007;56(7):1761. doi: $10.2337 / \mathrm{db} 06-1491$

24. Cani PD, Amar J, Iglesias MA, et al. Metabolic endotoxemia initiates obesity and insulin resistance. Diabetes. 2007;56(7):1761-1772.
25. Amyot J, Semache M, Ferdaoussi M, Fontés G, Poitout V. Lipopolysaccharides Impair Insulin Gene Expression in Isolated Islets of Langerhans via Toll-Like Receptor-4 and NF- $\mathrm{kB}$ Signalling. PLoS One. 2012;7(4):e36200. doi:10.1371/journal. pone. 0036200

26. Hou M, Venier N, Sugar L, et al. Protective effect of metformin in CD1 mice placed on a high carbohydrate-high fat diet. Biochem Biophys Res Commun. 2010;397(3):537-542. doi:10.1016/j. bbrc.2010.05.152

27. Kawasaki F, Matsuda M, Kanda Y, Inoue H, Kaku K. Structural and functional analysis of pancreatic islets preserved by pioglitazone in db/db mice. Am J Physiol Endocrinol Metab. 2005;288(3):E510. doi:10.1152/ajpendo.00128.2004

28. Molenaars M, Janssens GE, Williams EG, et al. A Conserved Mito-Cytosolic Translational Balance Links Two Longevity Pathways. Cell Metab. 2015;11(3):549-563. doi:10.1016/j. cmet.2020.01.011

29. Montanya E, Nacher V, Biarnés M, Soler J. Linear correlation between beta-cell mass and body weight throughout the lifespan in Lewis rats: role of beta-cell hyperplasia and hypertrophy. Diabetes. 2000;49(8):1341-1346. doi:10.2337/diabetes.49.8.1341

\section{Publish your work in this journal}

Diabetes, Metabolic Syndrome and Obesity: Targets and Therapy is an international, peer-reviewed open-access journal committed to the rapid publication of the latest laboratory and clinical findings in the fields of diabetes, metabolic syndrome and obesity research. Original research, review, case reports, hypothesis formation, expert opinion and commentaries are all considered for publication. The manuscript management system is completely online and includes a very quick and fair peer-review system, which is all easy to use. Visit http://www.dovepress.com/testimonials.php to read real quotes from published authors.

Submit your manuscript here: https://www.dovepress.com/diabetes-metabolic-syndrome-and-obesity-targets-and-therapy-journal 